\title{
Islet Cell Autoantibody and Glutamic Acid Decarboxylase-65 Autoantibody in Young Diabetic patients in a General Hospital of Dhaka City
}

\author{
Chowdhury $\mathrm{AK}^{1 *}$, Shahi $\mathrm{SR}^{2}$, Moniruzzaman $\mathrm{M}^{3}$, Khan $\mathrm{M}^{1}$ \\ ${ }^{I}$ Department of Immunology, BIRDEM General Hospital, Dhaka, Bangladesh; ${ }^{2}$ Department of \\ Oncology, Khawja Eunus Ali Medical College, Sirajgonj, Bangladesh; ${ }^{3}$ Department of Immunology, \\ Bangladesh University of Health Science, Dhaka, Bangladesh;
}

\begin{abstract}
Background: Immune mediated destruction of pancreatic beta cell in type-I diabetes is well established but its' role in young type- 2 diabetic patients is still not conclusive. These young diabetic patients pass through several stages where they do not need insulin but found to have serum autoantibody against islets cell and even become dependent on insulin for survival in course of time. This study aims to find the presence of islets cell auto-antibodies (ICA) and autoantibody to glutamic acid decarboxylase-65 (GAD65) in non-insulin requiring young diabetic patients of Bangladesh.
\end{abstract}

Objective: To evaluate the presence of ICA and GAD-65 between the non-insulin requiring young type-2 diabetic patients and compare with the non-diabetic control group.

Method: This case control study was carried out at the Department of Immunology, BIRDEM General Hospital, Dhaka for a period of one year from July 2013, A total of 120 non-insulin requiring $(\geq 12$ months) young type- 2 diabetic patients and 60 age, sex matched non-diabetic were enrolled as control subjects following inclusion and exclusion criteria. ICA and GAD-65 tests were performed by enzyme linked immune-sorbent assay (ELISA) method by using kits from DRG Inc. International, USA.

Results: In this study statistically significant difference found between non insulin requiring young diabetic patients and non diabetic control in respect of positive ICA result $(p=0.015)$. The moderately strong negative association was found between different age of onset of diabetes mellitus and value of ICA level $(\mathrm{r}=-0.45)$. Only 20-24 years age group showed statistically significant difference between patient and control $(p=0.013)$. Statistically significant difference was not found in GAD-65 values of non insulin requiring young diabetic patients and non diabetic controls $(p=0.441)$.

Conclusion: This study revealed that there is significant difference present in respect of ICA among noninsulin requiring young diabetic patients and non-diabetic controls. Therefore, autoimmune pathogenesis of beta cell killing by producing ICA against islets cell take place in young type-2 diabetic patients.

Keywords: Islet cell autoantibody, Glutamic acid decarboxylase-65, Latent autoimmune diabetes in youth, Type-2 diabetes

\section{Introduction}

Diabetes mellitus (DM) has proved to be one of the commonest non-communicable diseases which become major public health question in the modern world. DM characterized by hyperglycemia resulting from absolute insulin deficiency due to autoimmune $\beta$ cell destruction (in type-1 DM), decreased insulin secretion frequently on the background of insulin resistance due to progressive loss of adequate $\beta$ cell (in type$2 \mathrm{DM})$, during gestational period and for some other specific causes (e.g. neonatal DM. maturity onset DM of young, cystic fibrosis, pancreatitis, drug and chemical induced). ${ }^{1}$ Long-term and uncontrolled diabetes is associated with long-term

*Correspondence: Dr. Ashesh Kumar Chowdhury, Department of Immunology, BIRDEM General Hospital, Dhaka, Bangladesh;

e-mail:ashesh66@gmail.com; ORCID: 0000000271128373 damage, dysfunction, and failure of various organs, especially the eyes, kidneys, nerves, heart, and blood vessels. ${ }^{1}$ DM though previously considered less significant disease is now being seen as one of the most important threat to human health in 21 st century. ${ }^{2}$ Especially in the last two decades there has been an explosive increase in the number of people diagnosed with diabetes worldwide. According to International Diabetic Federation (IDF), approximately 425 million adults have diabetes; by 2045 this will rise to 629 million with $80.0 \%$ of the burden carried by lower middle income group countries like Bangladesh. ${ }^{3}$ It was reported that Bangladeshi people are more susceptible to develop obesity, diabetes, hypertension, and coronary artery diseases compared with other South Asian migrants (Indian, Pakistani) settled in United Kingdom. ${ }^{4}$ Previously 
diabetes was a disease of the first world, but now it has become a major public health problem in low and middle income countries, specially affecting South Asians. The economic and disease burden associated with diabetes puts enormous pressure on fragile health systems in low-income countries. In the South Asian region, Bangladesh has the second largest number of adults with diabetes. ${ }^{3}$

Type I diabetes pathogenesis occurs primarily due to autoimmune-mediated destruction of pancreatic B-cell islets. This results absolute insulin deficiency and patients must take exogenous insulin for survival to prevent the development of ketoacidosis. Type II diabetes is characterized by insulin resistance and/or abnormal insulin secretion, either of which may be major determining factor. Type II diabetes patients do not dependent on exogenous insulin, but to control blood glucose level it may work as an important factor if this is not achieved with diet alone or with oral hypoglycemic drugs. Classifying diabetes is still elusive and nebulous; some study has suggested that a classification considering etiology is superior to clinical judgment. ${ }^{5}$

Young diabetic patient who is not on insulin requiring at the time of diagnosis may need insulin and even become dependent on insulin for survival. ${ }^{6}$ Islet-reactive $\mathrm{T}$ cells responding to multiple islet proteins have been found in Type 2 DM patients with or without islet cell antibodies. ${ }^{7}$ Various islet auto-antibodies have historically been relied upon as indicators of the presence of islet autoimmunity in diabetes patients. The most common Islet Autoantibodies, which are ICA, GAD65, autoantibodies to insulin- the tyrosine phosphatases (IA-2 and IA$2 \beta$ ), and zinc transporter 8 (ZnT8). ${ }^{1}$ The rate of $\beta$ cell destruction is quite variable, being rapid in some individuals (mainly infants and children) and slow in others (mainly adults). ${ }^{1}$ In fact, positivity for an increasing number of islet autoantibodies associated with a progressively greater risk of developing' insulin dependency. ${ }^{8}$ GAD autoantibodies and ICAs are much more common than IA-2, IA-2 $\beta$, and ZnT8 autoantibodies. ${ }^{8}$ In the DAISY (The Diabetes Autoimmunity Study in the Young) cohort, $89.0 \%$ of children who progressed to diabetes expressed two or more autoantibodies. Age of diagnosis of diabetes is strongly correlated with development of auto-antibodies against pancreatic beta cell. ${ }^{9}$ Now a days in clinical practice, it has become increasingly difficult to distinguish type T1DM from T2DM in pediatric diabetic patient as many children with T1DM are overweight at diagnosis. Numerous recent publications note a significant proportion of physician- diagnosed T2DM youth with evidence of pancreatic autoimmunity, exemplifying the challenges in distinguishing between TIDM and T2DM. The clinical implications of the phenomenon of antibody positivity in phenotypic T2DM youth, also referred to as 'latent autoimmune diabetes in youth' (LADY), and 'hybrid diabetes', are unclear at present. ${ }^{10}$ In Bangladeshi population, Ashesh K. Chowdhury and his colleagues found that $60 \%$ of type 1 diabetes patient and $35 \%$ of type 2 diabetes patients were positive for islets cell autoantibody. ${ }^{12}$ The present study was concentrated to see the presence of ICA and GAD65 autoantibody in non-insulin requiring young diabetic patients in a tertiary care general hospital of Dhaka city and compare the findings with the non diabetic controls. These antibodies may appear in the progression of diabetes in young patients and evaluation of these antibodies is very crucial.

\section{Materials and Methods}

This was a case control study carried out at the Department of Immunology, BIRDEM General Hospital, Dhaka over a period of one year (July, 2013- June, 2014). A total of 120 young diabetic patients of both sex (age between 18-34 years) were randomly enrolled in this study who were diagnosed as diabetic and not taking insulin for at least one year as treatment. Patients aged more than 35 years, suffered by other co-morbid condition, other autoimmune disorders, insulin required in previous one year, history of ketosis in previous one year and pregnant women were excluded from the study. Sixty age and sexmatched non-diabetic healthy subjects were chosen as controls, case control ratio was (2:1). The cases were non insulin requiring diabetic patients of below 35 years of age and were registered patients in the Outpatient Department (OPD) of BIRDEM General Hospital. Criteria for the diagnosis of diabetes mellitus was fasting plasma glucose $($ FPG $) \geq 126 \mathrm{mg} / \mathrm{dl}(7.0 \mathrm{mmol} / \mathrm{l})$ and two hours after plasma glucose $\geq 200 \mathrm{mg} / \mathrm{dl}(11.1 \mathrm{mmol} / \mathrm{l})$ during an $75 \mathrm{gm}$ oral glucose tolerance test (OGTT) measured by Cobas c501 Automatic analyzer, Roche, Switzerland. The enzyme linked immune-sorbent assay (ELISA) test for ICA and GAD-65 was performed using the reagents from DRG Inc, USA following the manufacturer's instruction. 


\section{Results}

The study was done on 120 non-insulin requiring young diabetic patients with the mean $( \pm \mathrm{SD})$ age of $27.3( \pm 7.62)$ years and 60 nondiabetic control subjects with the mean $( \pm \mathrm{SD})$ age of $26.9( \pm 6.92)$ years. Study subjects were age matched in different age groups and percentage of gender distribution in both patient and control group were relatively close. (table I).

Table I: Age and gender distribution of the study subjects

\begin{tabular}{|c|c|c|c|c|}
\hline \multirow{3}{*}{$\begin{array}{l}\text { Sex } \\
\text { distribution }\end{array}$} & \multicolumn{2}{|c|}{ Patient $(n=120)$} & \multicolumn{2}{|c|}{ Control $(n=60)$} \\
\hline & Male & Female & Male & Female \\
\hline & $\begin{array}{c}69 \\
(57.5 \%)\end{array}$ & $\begin{array}{c}51 \\
(42.5 \%)\end{array}$ & $\begin{array}{c}36 \\
(60 \%)\end{array}$ & $\begin{array}{c}24 \\
(40 \%)\end{array}$ \\
\hline $\begin{array}{l}\text { Age } \\
\text { distribution } \\
20-24 \text { years }\end{array}$ & \multicolumn{2}{|c|}{$39(32 \%)$} & \multicolumn{2}{|c|}{$20(33 \%)$} \\
\hline $25-29$ years & \multicolumn{2}{|c|}{$72(60 \%)$} & \multicolumn{2}{|c|}{$36(60 \%)$} \\
\hline $30-34$ years & \multicolumn{2}{|c|}{$09(08 \%)$} & \multicolumn{2}{|c|}{$04(07 \%)$} \\
\hline $\begin{array}{l}\text { Mean } \\
( \pm \text { SD }) \text { age }\end{array}$ & \multicolumn{2}{|c|}{$27.3( \pm 7.62)$} & \multicolumn{2}{|c|}{$26.9( \pm 6.92)$} \\
\hline
\end{tabular}

Presence of ICA and GAD-65: Analysis of autoantibody positivity had shown that there was statistically significant difference between

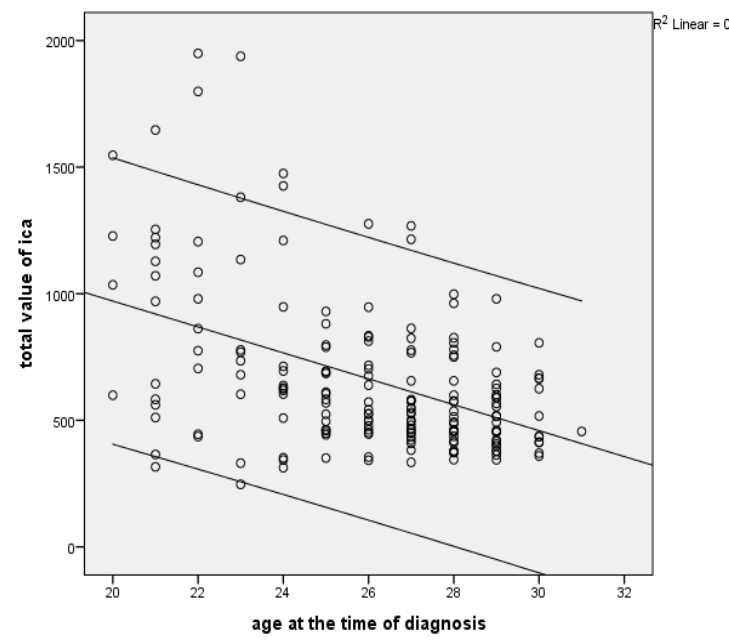

non-insulin requiring young diabetes patients and non-diabetic control subjects in respect of positive ICA result $(p=0.015)$. No statistically significant association was found between noninsulin requiring young diabetes and non diabetic control in respect of positive GAD-65 result ( $p=0.441)$ (table II).

Table II: Auto-antibodies (ICA and GAD-65) status in case and control.

\begin{tabular}{|c|c|c|c|c|c|c|}
\hline & \multicolumn{2}{|c|}{$\begin{array}{c}\text { Islet Cell } \\
\text { Autoantibodie } \\
\text { (ICA) }\end{array}$} & \multirow[t]{2}{*}{$\begin{array}{c}p \\
\text { value }\end{array}$} & \multicolumn{2}{|c|}{$\begin{array}{c}\text { Glutamic Acid } \\
\text { Decarboxylase } \\
65 \text { (GAD) }\end{array}$} & \multirow[t]{2}{*}{$\begin{array}{c}p \\
\text { valu }\end{array}$} \\
\hline & Positive & Negative & & Positive & Negative & \\
\hline \multirow[t]{2}{*}{$\begin{array}{l}\text { Patient } \\
(\mathrm{n}=120)\end{array}$} & $\begin{array}{c}25 \\
(20.8 \%)\end{array}$ & $\begin{array}{c}95 \\
(79.2 \%)\end{array}$ & & $\begin{array}{c}10 \\
(8.3 \%)\end{array}$ & $\begin{array}{c}110 \\
(9.7 \%)\end{array}$ & \\
\hline & & & 0.015 & & & 0.441 \\
\hline $\begin{array}{l}\text { Control } \\
(\mathrm{n}=60)\end{array}$ & $\begin{array}{c}04 \\
(6.7 \%)\end{array}$ & $\begin{array}{c}56 \\
(93.3 \%)\end{array}$ & & $\begin{array}{c}04 \\
(6.7 \%)\end{array}$ & $\begin{array}{c}56 \\
(93.3 \%)\end{array}$ & \\
\hline Total & 29 & 151 & & 14 & 166 & \\
\hline
\end{tabular}

Association of age of onset of diabetes with ICA and GAD-65 value: In this study, it was to be found that the age of onset of young diabetic people were negatively associated with serum ICA level $(r=-0.45)$. But GAD-65 did not show such statistically significant correlation $(r=-0.176)$ with age of onset of young diabetic population.

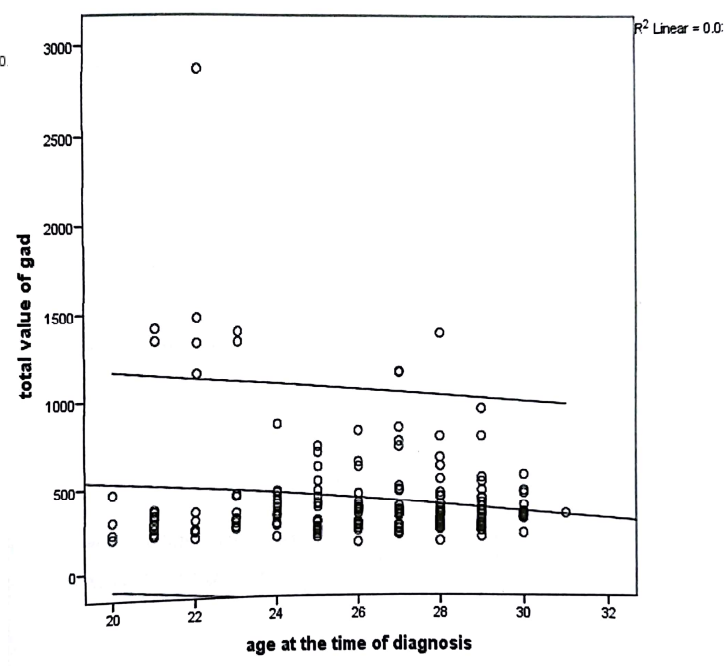

Figure 1: Association of age of onset of diabetes with ICA and GAD-65 value

Difference in ICA autoantibody in different age group: Here it was categorised both diabetic patient and control in three groups according to age of onset and found difference in ICA positivity. The 20-24 years age group showed statistically significant $(p=0.013)$ difference in serum ICA level among patient and control than other age group. Most interestingly more than 30 years age group did not showed a single positive case in both patient and control group (figure 2). 

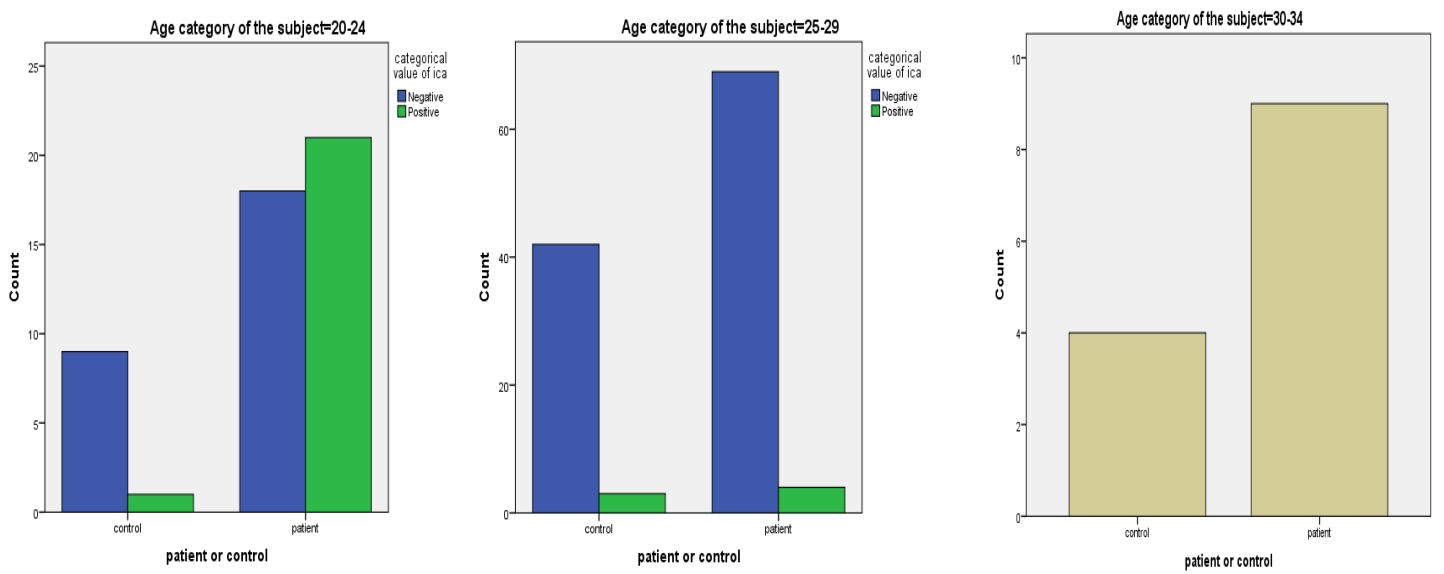

Figure 2: Difference in ICA autoantibody in different age group

\section{Discussion}

In this study it was to be found that ICA positivity had statistically significant difference between non-insulin requiring young diabetic patient and the non diabetic controls. But Verge et al concluded that ICA level has, the least significant result among all five auto-antibodies they have used. This discordance between the works may be due the difference in sample collection. As in this study subjects were taken from the non insulin requiring diabetic patients but they have taken type I diabetic patient as their subjects. This gives an insight that non insulin requiring and type I diabetic patient may have different autoantibody markers. ${ }^{11}$

In a previous study by Ashesh et al found the presence of autoimmunity in more than one-third patients. That study enrolled seventy patients as case including twenty type 1 diabetes patients, forty type 2 diabetic patients and ten patients belong to Fibrocalculous Pancreatic Diabetes (FCPD) group. $60 \%$ of type 1 diabetes case was positive with either for GAD or ICA and $30 \%$ patients of the FCPD group had only GAD positivity. The most fascinating aspect of their study was that $27.5 \%$ of clinically diagnosed type 2 patients were positive with autoantibody (GAD and/or ICA) suggesting that they might fit into LADA category..$^{12}$ In a recent study conducted by Islam $\mathrm{N}$ et al described the increased presence of GAD antibody level $(10.0 \%)$ in newly diagnosed adult diabetic patients (mostly more than 35 years of age). ${ }^{13}$ But here it did not found significant GAD positivity in this study, as of previous study in young diabetic patients of less than 30 years of age. $^{12}$ In the present study, it was found the ICA was significantly high in young diabetic patients (mostly below 25 years of age). Moreover, the sample size of the present study was larger than previous studies and patients' group were more selective. This study also concentrated more on a specific group of patients who are vulnerable to develop insulin dependent diabetes.

Irvine et al found that duration of diabetes has strong correlation with islets cell autoantibody level. In this research, no statistically significant correlation between duration of diabetes and autoantibody markers was found. They also found that autoantibody has strong correlation with coexisting autoimmune disease. But in this study it was excluded patients with other autoimmune disease. As one autoimmune disease increases chances other autoimmune autoantibody formation. So, the study which had taken patients with autoimmune disease includes a confounding variable. Verge et al also found that GAD-65 has strong correlation with diabetic patient. But we did not found any statistically significant relation in case GAD-65. This difference may be due to sampling variation and this also shows that autoimmune cause of diabetes in this population might be of different pathology other than their Caucasian patient group. ${ }^{11}$

\section{Conclusion}

Non-insulin requiring young diabetic patients showed significant difference in islets cell autoantibody. Youngest (20-24 yrs) age group showed more ICA positivity than other age groups. Autoimmune pathogenesis of beta cell killing by producing ICA against islets cell take place in young diabetic patients. These ICA positive young diabetic patients will lose their beta cell function more rapidly and will be dependent on insulin for survival. Therefore, prospective large scale multicenter based study is required to validate precise role of other islet cell autoantibody like IA2, IA-2 $\beta$ and ZnT8. 


\section{Acknowledgements}

This project was funded by Bangladesh Medical Research Council in 2013-14 fiscal year. We would like to thank Dr. Moushumi Dey and Md. Abu Taher Sarker for their technical and intellectual support.

Conflict of Interests: There was no conflict of interests present in this study.

Funding: Bangladesh Medical Research Council (BMRC).

Ethical Clearance: National Ethics Review Committee of BMRC.

Submitted: $01^{\text {st }}$ February, 2018

Final revision received: $15^{\text {th }}$ March, 2020

Accepted: $19^{\text {th }}$ March, 2020

Published: $1^{\text {st }}$ August, 2020

\section{References}

1. American Diabetes Association. Classification and Diagnosis of Diabetes: Standards of Medical Care in Diabetes- 2020. Diabetes Care. 2020, 43 (Suppl.1): s14-s31.

2. Zimmer P. Globalization, coca-colonization and the chronic disease epidemic: can the doomsday scenario be averted? Journal of Internal Medicine. 2020; 247: 301-10.

3. International Diabetes Federation. IDF Diabetes Atlas, 8th edn. Brussels, Belgium: International Diabetes Federation. 2017.

4. Shah A, Kanaya AM. Diabetes and Associated Complications in the South Asian Population. Current cardiology reports. 2014; 16: 476.

5. Borg H, Arnqvist HJ, Bjork E, Bolinder J, Eriksson JW, Nystrom L et al Evaluation of the new ADA and WHO criteria for classification of diabetes mellitus in young adult people (15-34 yrs) in the Diabetes Incidence Study in Sweden (DISS). Diabetologia. 2003; 46: 173-81.

6. Lipton RB. Incidence of diabetes in children and youth- tracking a moving target. Journal of American Medical Association. 2007; 297: 2760-62.
7. Mayer A, Fabien N, Gutowski MC, Dubois V, Gebuhrer L, Bienvenu J et al Contrasting cellular and humoral autoimmunity associated with latent autoimmune diabetes in adults. European Journal of Endocrinology. 2007 157: 53-61.

8. Winter WE, Harris N, Schartz D (2002). Immunological Markers in the Diagnosis and Prediction of Autoimmune Type 1 Diabetes. Clinical Diabetes. 2002; 20: 183-91.

9. Barker JM, Barriga KJ, Yu L, Miao D, Erlich HA, Norris $\mathrm{M}$ et al. Prediction of Autoantibody Positivity and Progression to Type I Diabetes: Diabetes Autoimmunity Study in the Young (DAISY). Journal of Clinical Endocrinology \& Metabolism. 2004; 89: 3896-902.

10. Pihoker C, Gilliam LK, Hampe CS, Lemmark A. Autoantibodies in Diabetes. Diabetes. 2005;54: 52-61.

11. Verge CF, Stenger D, Bonifacio E, Colman PO, Pilcher C, Eisenbarth GS et al. Combined use of autoantibodies (IA-2 autoantibody, GAD autoantibody, insulin autoantibody, cytoplasmic islet cell antibodies) in type 1 diabetes: Combinatorial Islet Autoantibody Workshop. Diabetes. 1998;47. 1857-66.

12. Chowdhury AK, Karim A, Bakshi SK, Ahmed T. Autoantibodies (glutamic acid decarboxylase and islet cell autoantibody) in subsets of diabetic patients (Type 1, Type 2 and fibrocalculous pancreatic diabetes) of Bangladesh. Bangladesh Journal of Pathology. 2012 27: 97-102.

13. Islam $\mathrm{N}$, Begum $\mathrm{T}$, Chowdhury $\mathrm{AK}$, Umarah $\mathrm{M}$, Alam MS, Khan NS et al. Glutamic acid decarboxylase positivity in selected group of Bangladeshi type 2 diabetic patients. BIRDEM Medical Journal. 2019; 9: 213-217.

14. Irvine $\mathrm{WJ}$, McCallum CJ, Gray RS, Campbell CJ, Duncan LJ, Farquhar JW et al. Pancreatic islet-cell antibodies in diabetes mellitus correlated with the duration and type of diabetes, coexistent autoimmune disease, and HLA type. Diabetes. 1977; 26:138-47. 